Original papers

\title{
Assessing a novel smartphone application - SnapCard, compared to five imaging systems to quantify droplet deposition on artificial collectors
}

\author{
J. Connor Ferguson ${ }^{\mathrm{a}, \mathrm{b}, *}$, Rodolfo G. Chechetto ${ }^{\mathrm{a}, \mathrm{c}}$, Chris C. O’Donnell ${ }^{\mathrm{a}}$, Brad K. Fritz ${ }^{\mathrm{d}}$, W. Clint Hoffmann ${ }^{\mathrm{d}}$, \\ Chet E. Coleman ${ }^{\mathrm{d}}$, Bhagirath S. Chauhan ${ }^{\mathrm{e}}$, Steve W. Adkins ${ }^{\mathrm{a}}$, Greg R. Kruger ${ }^{\mathrm{f}}$, Andrew J. Hewitt ${ }^{\mathrm{a}, \mathrm{f}}$ \\ a The University of Queensland, Gatton, Queensland 4343, Australia \\ ${ }^{\mathrm{b}}$ Northwest Missouri State University, Maryville, MO 64468, United States \\ ' São Paulo State University - FCA, Department of Rural Engineering, Botucatu, São Paulo 18610, Brazil \\ ${ }^{\mathrm{d}}$ USDA ARS, 2771 FEB Road, College Station, TX 77845, United States \\ e Queensland Alliance for Agriculture and Food Innovation (QAAFI), The University of Queensland, Toowoomba, Queensland 4350, Australia \\ ${ }_{\mathrm{f}}$ University of Nebraska-Lincoln, North Platte, NE 69101, United States
}

\section{A R T I C L E I N F O}

\section{Article history:}

Received 30 April 2016

Received in revised form 1 July 2016

Accepted 29 August 2016

Available online 14 September 2016

\section{Keywords:}

Image analysis

Kromekote

Water-sensitive paper

SnapCard

Smartphone App

Sprays

Droplet size

Spray quality

\begin{abstract}
A B S T R A C T
Previous work sought to compare the results from imaging software for characterising droplet coverage, but none exists examining these five software programs: Droplet Scan ${ }^{\circledR}$, Swath $\mathrm{Kit}^{\circledR}$, Deposit Scan, Image J, and Drop Vision ${ }^{\circledR}$-Ag. Additionally, a freely available smartphone application (App), SnapCard was developed to provide an extension tool for in-field analysis of spray collectors, but nothing has been published regarding its comparison to other imaging software systems. The present study was conducted to compare five existing imaging software types against the new App, SnapCard. Six nozzles producing different spray qualities were selected to spray a water + Brilliant Blue Dye solution over two artificial collector types (water sensitive paper and Kromekote ${ }^{\circledR}$ ). Each collector was assessed for percent coverage using the five imaging systems and SnapCard. Objectives of this study were: 1 . To establish a baseline dataset using the sprayed cards and five commonly used imaging systems, and compare the coverage results from each. 2. Use the baseline data from Objective 1 as a measurement of precision to judge the results from SnapCard. 3. Make an assessment of SnapCard against the other imaging software type data in the study.

Results showed that SnapCard has similar measured coverage means compared to other image analysis systems. For both collector types, SnapCard measured coverage within one standard deviation of the means across nozzle types. SnapCard is able to provide an immediate answer without expensive software or needing a laboratory to measure sprayed collector coverage with precise results, which further underscores its value. The other software types were not all similar for coverage, but the data followed the same trends for droplet size. Increasing the droplet size consistently decreased the coverage, across both collector types. Droplet Scan reported the highest coverage while Drop Vision-Ag and Swath Kit gave lower coverage values on water sensitive paper and Kromekote ${ }^{\circledR}$ collectors, respectively.
\end{abstract}

(c) 2016 Elsevier B.V. All rights reserved.

\section{Introduction}

Pesticide spray applications are most effective when they result in maximum coverage and droplet distribution on plant material. Global pesticide applications have been increasing each year, up $10 \%$ between 2002 and 2010 in the US alone (Osteen and Fernandez-Cornejo, 2013). Selecting for optimal sprayer set-up and application technology, will improve the evenness and effec-

* Corresponding author at: Northwest Missouri State University, Maryville, MO 64468, United States.

E-mail address: cferguson@nwmissouri.edu (J.C. Ferguson). tiveness of each application, reducing the likelihood of the need for further applications (Uk and Courshee, 1982). This can save growers and applicators time and money in the long-term. Improving coverage increases the pesticide dose on each plant in most cases, which in turn helps maximise the efficacy of a plant protection product (Courshee, 1960; Knoche, 1994; Wolf et al., 2000). Proper technology selection requires the use of quantifiable methods to understand differences in application parameters (Ferguson et al., 2015).

Droplet deposition is quantified with the use of artificial collectors which also allow for a visualisation of coverage. The use of water sensitive paper (WSP), a paper collector treated with bro- 
moethyl blue which turns blue in the presence of water, for droplet deposition, is well documented (Turner and Huntington, 1970; Hill and Inaba, 1989). WSP and the results they provide are well accepted to help growers and applicators select optimal application parameters and technologies, but need further processing beyond the visible coverage alone (Syngenta, 2002). WSP collectors allow for a spray solution to be applied as a tank mixture for application without additional spray solution inputs - allowing for exact droplet deposition analysis of the spray (Hill and Inaba, 1989). Another widely used artificial collector is Kromekote $^{\circledR}$ paper, a speciality photographic paper that stains when a droplet containing a dye deposits on it. This collector type has been used substantially to characterise sprays (Johnstone, 1960; Higgins, 1967; Hewitt and Meganasa, 1993). Other artificial collector types like Petri dishes, Mylar ${ }^{\circledR}$ sheets, pipe cleaners, alpha cellulose cards, and glass slides have been used to quantify droplet deposition (Hewitt, 2010; Lee et al., 1978; Degre et al., 2001; Hoffmann and Hewitt, 2005) but are not able to be readily assessed using imaging software. WSP collectors provide useful and accurate measures of the deposited spray droplets to help gauge outcomes of applications (Hoffmann and Hewitt, 2005; Wolf, 2003; Hill and Inaba, 1989). Additionally, WSP spread factors are well known and documented, which further supports accurate data evaluation.

Imaging techniques for droplet deposition are not new (Carlton, 1967; Bouse et al., 1990) and the development of accurate software for the visual characterisation of droplet deposition has been ongoing since 1985 (Ahlers and Alexander, 1985; Carlton and Bouse, 1981; Franz, 1993). Several imaging systems have been developed to characterise and quantify droplet deposition and have been found to provide reasonable data: Swath $\mathrm{Kit}^{\circledR}$ (Hoffmann and Hewitt, 2005; Mierzejewski, 1991), USDA Image Analyzer (Hoffmann and Hewitt, 2005); Droplet Scan ${ }^{\circledR}$ (Hoffmann and Hewitt, 2005; Wolf, 2003), Deposit Scan (Zhu et al., 2011); Image J (Rasband, 2008), and Drop Vision ${ }^{\circledR}-\mathrm{Ag}$ (Leading Edge Associates, 2015). Comparisons of these programs have been less than consistent, where some programs have strong correlations, while others had great variability (Hoffmann and Hewitt, 2005; Cunha et al., 2011; Cunha et al., 2013). Swath Kit ${ }^{\circledR}$, Droplet Scan ${ }^{\circledR}$, and Drop Vision- $\mathrm{Ag}^{\circledR}$ were developed specifically to characterise sparsely sprayed collectors to produce an overall estimate of swath consistency and evenness for aerial applicators (Wolf, 2003; Mierzejewski, 1991; Leading Edge Associates, 2015). This is contrasted with Deposit Scan and Image J, which were developed specifically to characterise a given image, rather than produce a composite curve across a boom swath (Zhu et al., 2011; Rasband, 2008).

With continual developments in technology, advances in portable electronics have provided further possibilities for agricultural data analysis in the field. A freely available smart phone application, SnapCard (SNP) (http://agspsrap31.agric.wa.gov.au/snapcard/) has been developed by the University of Western Australia and the Department of Agriculture and Food Western Australia (DAFWA) as an extension tool to measure droplet deposition in the field on WSP and Kromekote ${ }^{\circledR}$ collectors (Nansen et al., 2015). This smartphone App utilises the camera on the phone and through the application, calculates the coverage on sprayed collectors scanned into the program. SnapCard was developed specifically for extension purposes to provide an in-field tool for measuring coverage by applicators on the go, which further makes the App unique (Nansen et al., 2015).

The objectives of this study were to: 1 . To establish a baseline dataset using the sprayed cards and five commonly used imaging systems, and compare the coverage results from each. 2 . Use the baseline data from Objective 1 as a measurement of precision to judge the results from SnapCard. 3. Make an assessment of SnapCard against the other imaging software type data in the study.

\section{Materials and methods}

A study to assess the measured coverage of a novel smart phone application against existing image analysis software was conducted at the University of Queensland in Gatton, Queensland (QLD), Australia and at the United States Department of Agriculture (USDA) Agricultural Research Service (ARS) Aerial Application Technology Research Unit in College Station, Texas, USA.

\subsection{Spray application of the collectors}

Water sensitive paper (Novartis International AG, Basel Switzerland), and Kromekote ${ }^{\circledR}$ collectors were sprayed with water plus a $1 \mathrm{~g} \mathrm{~L}^{-1}$ addition of Brilliant Blue (Tintex Dyes, Kelvin Grove, QLD Australia), using a trailed sprayer (UA300B/20S/6BX, Croplands Equipment Pty. Ltd., Adelaide, SA, Australia) with a $6 \mathrm{~m}$ spray boom pulled behind an all-terrain vehicle (Yamaha Grizzly 350, Yamaha Motor Pty. Ltd., Wetherill Park, NSW, Australia). Dye was added as the Kromekote ${ }^{\circledR}$ collectors were used to quantify droplet deposition. Nozzles used in the study were the ASABE/ANSI S572.1 Ground Reference Nozzles (ASAE, 2009) at their respective reference pressures (Table 1). By selecting these nozzles, we had a treatment with each of the six common spray qualities (Fine, Medium, Coarse, Very-Coarse, Extremely-Coarse and Ultra-Coarse) used in agricultural spray application (Table 1).

Treatments with each nozzle at its respective reference pressure were all applied at a common $187 \mathrm{~L} \mathrm{ha}^{-1}$ application volume rate. Driving speeds for each treatment (Table 2) varied in order to achieve the constant application volume rate. Collectors were placed on flat metal plates, $10 \mathrm{~cm}$ above the ground and arranged in two vertical lines with $1 \mathrm{~m}$ spacing and with three collectors of each type per treatment. Each nozzle treatment was replicated three times producing nine sprayed collectors of each collector type for each treatment. Kromekote ${ }^{\circledR}$ and WSP collectors were $76 \mathrm{~mm} \times 26 \mathrm{~mm}$. Boom heights varied (Table 2) based on nozzle type in order to maintain a $50 \%$ spray pattern overlap for each nozzle type.

\subsection{Droplet deposition software}

Collectors from the application study were individually assessed for percent coverage using five different image analysis software programs available for droplet deposition analysis.

\subsubsection{Software at the University of Queensland}

Individual collectors were measured at the University of Queensland using Swath $\mathrm{Kit}^{\circledR} 3.0$ (SWT) (Droplet Technologies, State College, PA, USA), Image J (IJ) (National Institute of Health, Washington DC, USA) (Rasband, 2008), and Deposit Scan (DEP) (USDA-ARS, Wooster, Ohio, USA). Sprayed collectors for IJ and DEP were scanned into the computer using a $12 \mathrm{MP}$ digital single-lens reflex (DSLR) camera (Nikon D60, Nikon Inc., Melville, NY, USA). In IJ, a sprayed collector was selected and then the image was cropped to remove any area around the collector to continue analysis. The sprayed collector was then analysed with the software in 8-bit mode and the threshold was visually adjusted to include only the sprayed droplets, excluding non-droplets from the image. Adjusted, images were transformed to monochrome (i.e. black droplets on a white background), at which point they were assessed for coverage using the "Measure" function in IJ. Methods for measuring coverage in DEP were similar to those described for IJ, as the program runs from an IJ platform. Detailed instructions on sprayed collector preparation for deposition analysis with DEP are published (Zhu et al., 2011). Collectors for SWT were individually scanned using the system's own Pulnix TM-7 
Table 1

Measured droplet size distribution $\left(D_{\mathrm{v} 0.1}, D_{\mathrm{v} 0.5}\right.$ and $\left.D_{\mathrm{v} 0.9}\right)$ for ASABE/ANSI S572.1 reference nozzles with water using a laser diffraction instrument.

\begin{tabular}{|c|c|c|c|c|c|}
\hline Nozzle & $\begin{array}{l}\text { Pressure } \\
\mathrm{kPa}\end{array}$ & $\begin{array}{l}\mathrm{D}_{\mathrm{v} 0.1} \\
\mu \mathrm{m}\end{array}$ & $\mathrm{D}_{\mathrm{v} 0.5}$ & $\mathrm{D}_{\mathrm{v} 0.9}$ & ASABE/ANSI classification \\
\hline 11001 & 450 & 57 & 112 & 198 & Very-Fine/Fine \\
\hline 11003 & 300 & 95 & 220 & 381 & Fine/Medium \\
\hline 11006 & 200 & 180 & 373 & 593 & Medium/Coarse \\
\hline 8008 & 250 & 222 & 456 & 730 & Coarse/Very-Coarse \\
\hline 6510 & 200 & 288 & 585 & 956 & Very-Coarse/Extremely-Coarse \\
\hline 6515 & 150 & 382 & 729 & 1115 & Extremely-Coarse/Ultra-Coarse \\
\hline
\end{tabular}

Table 2

Application speed, boom height and application volume rate for each ASABE/ANSI S572.1 reference nozzle type used in the study.

\begin{tabular}{cccc}
\hline Nozzle & $\begin{array}{c}\text { Driving speed } \\
\mathrm{km} \mathrm{h}^{-1}\end{array}$ & $\begin{array}{l}\text { Boom height } \\
\mathrm{cm}\end{array}$ & $\begin{array}{l}\text { Application Volume rate } \\
\mathrm{L} \mathrm{ha}^{-1}\end{array}$ \\
\hline 11001 & 3.1 & 28 & 187 \\
11003 & 7.6 & 28 & 187 \\
11006 & 12.4 & 28 & 187 \\
8008 & 18.5 & 46 & 187 \\
6510 & 20.7 & 58 & 187 \\
6515 & 31.6 & 58 & 187 \\
\hline
\end{tabular}

series charge-coupled device (CCD) black and white camera (JAI Inc., San Jose, CA, USA). The Swath Kit $^{\circledR}$ was used to measure an area of $1.96 \mathrm{~cm}^{2}$ and take four images of the sprayed collectors through a middle swath of each card with the camera window to create a composite result for each collector.

\subsubsection{Software at USDA-ARS College Station}

Sprayed collectors were measured at the USDA-ARS Aerial Application Technology Research Unit in College Station, Texas using Droplet Scan $^{\circledR}$ (DRP) (WRK of Oklahoma, Stillwater, OK, USA) and Drop Vision ${ }^{\circledR}-\mathrm{Ag}$ (DVA) (Leading Edge Associates Inc, Fletcher, NC, USA). Sprayed collectors were scanned into DRP using a 200 dpi flat-bed scanner (HP Scanjet 8200, Hewlett-Packard Co., Palo Alto, CA, USA). Collectors for DVA were scanned using a 300 dpi (dots per inch) business card scanner (Scanshell 800 NR, Acuant Inc., Culver City, CA, USA).

\subsubsection{Scanning sprayed collectors through SnapCard}

Sprayed collectors were analysed for coverage through the SNP application (Nansen et al., 2015) on August 11th, 2015 using a smart phone (Samsung Galaxy S3, Samsung GEC, Seoul, South Korea) equipped with an $8 \mathrm{MP}$ camera and Android operating system (Android 4.1.2 (Jelly Bean), Google Inc, Mountain View, CA, USA). Developers of SNP created a best-use manual for scanning collectors through the system, http://agspsrap31.agric.wa.gov.au/ snapcard/\#manual and the collectors in the present study were measured using those guidelines. Fig. 1 shows the opening screen of SNP, the crop tool to select the area for analysis and then the final measured coverage.

\subsection{Statistical analyses}

Water sensitive paper and Kromekote ${ }^{\circledR}$ collector coverage were analysed in separate generalised linear mixed models (PROC GLIMMIX) in SAS (Statistical Analysis Software, version 9.4, Cary, North Carolina, USA) with means separations made at the $\alpha=0.05$ level. Both collector type models were analysed separately by the model: nozzle type coverage $=$ software type $\times$ replication. Fixed effects were the software types. Replication was treated as a random effect. The denominator degrees of freedom (df) was protected from bias through the inclusion of the Kenward-Roger adjustment for the generalised linear mixed model (Kenward and Roger, 1997).
The Sidak adjustment was included in comparisons of variables to improve the power and confidence in reported differences (Sidak, 1967). Additionally a simple $t$-test comparing means from the five imaging software types to SNP data was constructed for each collector type and carried out.

\section{Results}

\subsection{Water sensitive paper coverage by software type}

The simple $t$-test between the means from the five imaging software types compared to SNP data was not significant $(\mathrm{P}=0.92)$. The $t$-test showed that SNP precisely measured percent coverage as compared to the five imaging systems currently used in the industry. In the generalised linear mixed model, software type was significant $(\mathrm{P}<0.001)$ for measured coverage within each nozzle type model. DRP measured the highest coverage for each nozzle type with WSPs except the 6515 , where SNP resulted in the highest coverage (Table 3 ). DVA measured the lowest coverage by nozzle type, except for the 11001, where SWT resulted in the lowest coverage. SNP was always similar to IJ and DEP across each nozzle type, and was similar to DRP for the 8008 and 6515. The mean and standard deviation were calculated for each nozzle type and reported in Table 3 .

Means and standard deviations were calculated absent the SNP data in order to provide the baseline with which to compare. SNP, IJ, and DEP were within one standard deviation of the mean across all nozzle types, whereas SWT, DVA and DRP fell outside that window. The results across the software types split into three main groups: DRP alone, IJ, SNP, and DEP were similar in the second group, and SWT and DVA similar in the third group. Across nozzle types, SNP, IJ and DEP were similar, observing twice the coverage from SWT and DVA.

\subsection{Kromekote ${ }^{\circledR}$ coverage by software type}

The simple $t$-test between the means from the five imaging software types compared to SNP data was not significant $(\mathrm{P}=0.48)$. As with the WSP, the $t$-test showed that SNP precisely measured percent coverage as compared to the five imaging systems currently used. In the generalised linear mixed model, software type was significant for measured coverage with Kromekote ${ }^{\circledR}$ collectors $(\mathrm{P}<0.001)$ within each nozzle type model. SNP resulted in the highest measured coverage for each nozzle type except the 11001, where DEP recorded the highest coverage (Table 4). SWT resulted in the lowest coverage across nozzle type except with the 6515 where it resulted in the same coverage as DVA. SWT and DVA were similar across nozzle type except for the 11006, where SWT recorded a lower coverage than DVA. Kromekote ${ }^{\circledR}$ collectors were only able to be measured by DRP with the finest spray quality nozzle (11001), and this result was similar to 11001 coverage observed by IJ, SNP and DEP. IJ, DEP, and DRP were all within one standard deviation of the mean across each of the measured nozzle types, which for DRP was only the 


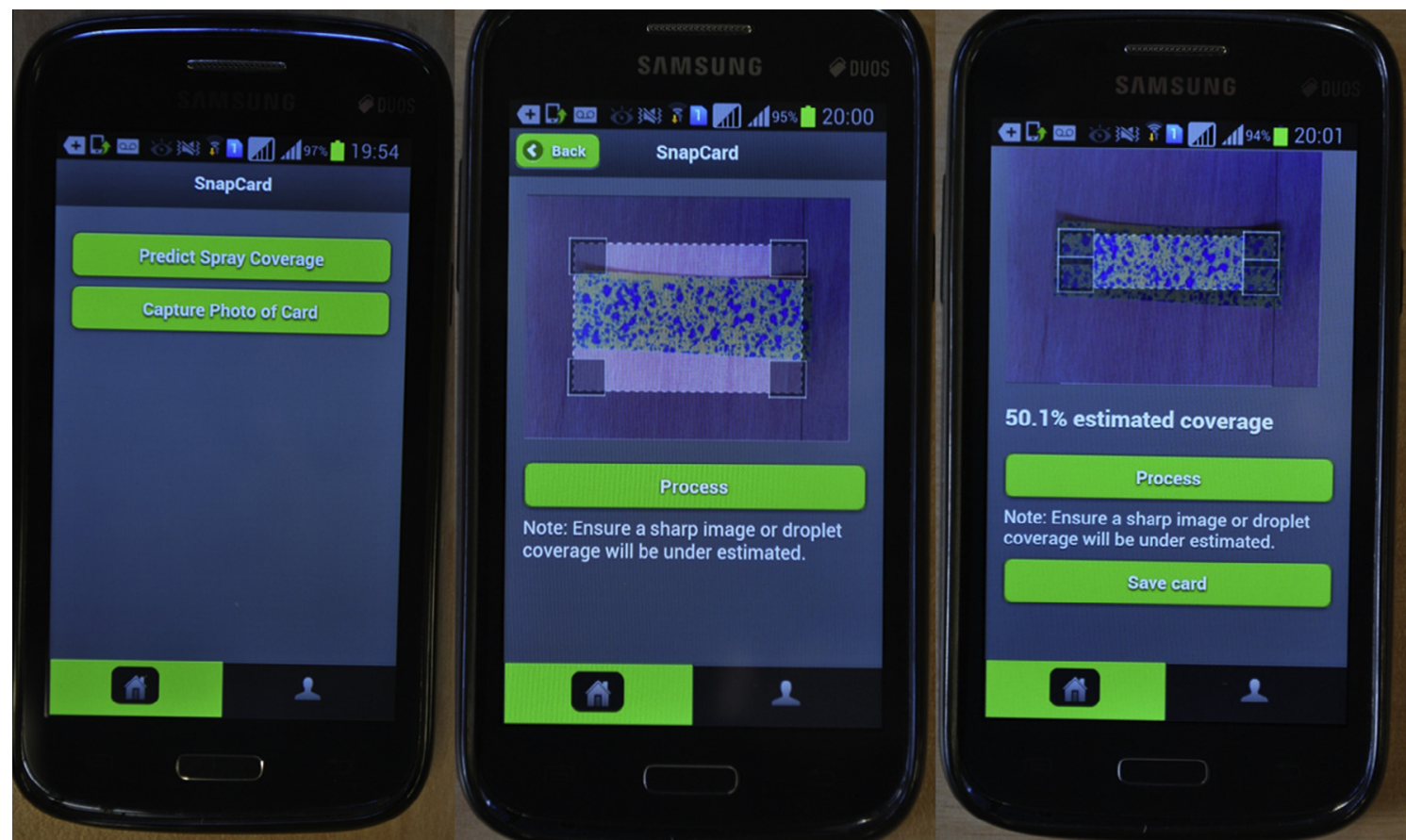

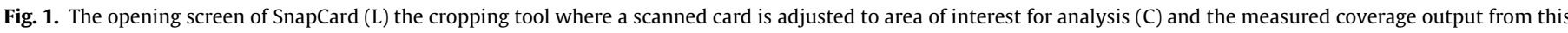
WSP sprayed using an $8008(\mathrm{R})$.

Table 3

Measured coverage (\%) on WSP for each nozzle type across each of the six imaging systems used in the study.

\begin{tabular}{|c|c|c|c|c|c|c|c|c|c|}
\hline Nozzle & Pressure (kPa) & SnapCard & Image J & Deposit scan & Swath kit & Drop vision-Ag & Droplet scan & $\begin{array}{c}\text { Mean } \\
\%\end{array}$ & $\begin{array}{c}\text { Standard deviation } \\
\sigma \sigma\end{array}$ \\
\hline 11001 & 450 & 49 B & $60 \mathrm{~B}$ & $60 \mathrm{~B}$ & $18 \mathrm{C}$ & $20 \mathrm{C}$ & $75 \mathrm{~A}$ & 46.6 & 25.9 \\
\hline 11003 & 300 & $49 \mathrm{~B}$ & $53 \mathrm{~B}$ & $53 \mathrm{~B}$ & $24 \mathrm{C}$ & $16 \mathrm{D}$ & $71 \mathrm{~A}$ & 43.4 & 22.8 \\
\hline 11006 & 200 & $51 \mathrm{~B}$ & $53 \mathrm{~B}$ & $52 \mathrm{~B}$ & $18 \mathrm{C}$ & $13 \mathrm{D}$ & $75 \mathrm{~A}$ & 42.2 & 26.1 \\
\hline 8008 & 250 & $43 \mathrm{~A}$ & $44 \mathrm{~A}$ & $43 \mathrm{~A}$ & $28 \mathrm{~B}$ & $18 \mathrm{C}$ & $50 \mathrm{~A}$ & 36.6 & 13.2 \\
\hline 6510 & 200 & $48 \mathrm{~B}$ & $50 \mathrm{~B}$ & $49 \mathrm{~B}$ & $26 C$ & $19 \mathrm{C}$ & $65 \mathrm{~A}$ & 41.8 & 18.9 \\
\hline 6515 & 150 & $25 \mathrm{~A}$ & $23 \mathrm{~A}$ & $24 \mathrm{~A}$ & $13 \mathrm{~B}$ & $9 \mathrm{~B}$ & $23 \mathrm{~A}$ & 18.4 & 6.9 \\
\hline
\end{tabular}

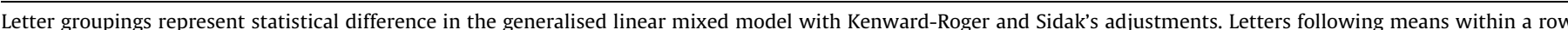
indicate significant differences at $\alpha=0.05$. Means and standard deviations were calculated without SnapCard data to provide the baseline for comparison.

Table 4

Measured coverage (\%) on Kromekote ${ }^{\circledR}$ collectors for each nozzle type across each of the six imaging systems used in the study.

\begin{tabular}{|c|c|c|c|c|c|c|c|c|c|}
\hline Nozzle & Pressure (kPa) & SnapCard & Image J & Deposit scan & Swath kit & Drop vision-Ag & Droplet scan & $\begin{array}{c}\text { Mean } \\
\%\end{array}$ & $\begin{array}{c}\text { Standard deviation } \\
\sigma\end{array}$ \\
\hline 11001 & 450 & $47 \mathrm{~A}$ & $46 \mathrm{~A}$ & $48 \mathrm{~A}$ & $19 \mathrm{~B}$ & $25 \mathrm{~B}$ & $42 \mathrm{~A}$ & 36.0 & 13.1 \\
\hline 11003 & 300 & $46 \mathrm{~A}$ & $40 \mathrm{~B}$ & $41 \mathrm{~B}$ & $21 \mathrm{C}$ & $24 \mathrm{C}$ & $\mathrm{N} / \mathrm{A}^{*}$ & 31.5 & 10.5 \\
\hline 11006 & 200 & $42 \mathrm{~A}$ & $34 \mathrm{~B}$ & 37 B & $18 \mathrm{D}$ & $25 \mathrm{C}$ & $\mathrm{N} / \mathrm{A}^{*}$ & 28.5 & 8.7 \\
\hline 8008 & 250 & $34 \mathrm{~A}$ & $29 \mathrm{~B}$ & $32 \mathrm{AB}$ & $16 \mathrm{C}$ & $20 \mathrm{C}$ & $\mathrm{N} / \mathrm{A}^{*}$ & 26.2 & 7.8 \\
\hline 6510 & 200 & $37 \mathrm{~A}$ & $33 \mathrm{~B}$ & $34 \mathrm{AB}$ & $17 \mathrm{C}$ & $20 \mathrm{C}$ & $\mathrm{N} / \mathrm{A}^{*}$ & 26.0 & 8.8 \\
\hline 6515 & 150 & $19 \mathrm{~A}$ & $16 \mathrm{~A}$ & $18 \mathrm{~A}$ & $11 \mathrm{~B}$ & $11 \mathrm{~B}$ & $\mathrm{~N} / \mathrm{A}^{*}$ & 14.0 & 3.6 \\
\hline
\end{tabular}

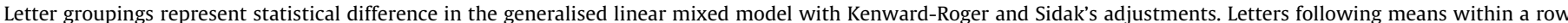
indicate significant differences at $\alpha=0.05$. Means and standard deviations were calculated without SnapCard data to provide the baseline for comparison.

N/A indicates that sprayed collectors from the nozzle treatment were not able to be analysed and therefore the data are excluded.

11001. SNP was within one standard deviation for the 11001 and 6510 , and within two standard deviations for the other nozzles.

\section{Discussion}

\subsection{Water sensitive paper coverage}

SNP coverage data were similar across all nozzle types to DEP and IJ. This result may not be surprising given that SNP was devel- oped from data obtained through IJ scans (Nansen et al., 2015) and DEP likewise was developed from an IJ platform (Zhu et al., 2011). The imaging systems that measured coverage different from SNP, IJ and DEP were outside two standard deviations of the mean across nozzle types. SWT, DVA, and DRP were specifically developed for characterising complete swaths of sprays in order to improve calibration of sprayers, especially aerial applications (Wolf, 2003; Mierzejewski, 1991; Leading Edge Associates, 2015). These software systems (SWT, DVA, and DRP) have built-in correction factors based on the type of application, and collector which is in contrast 

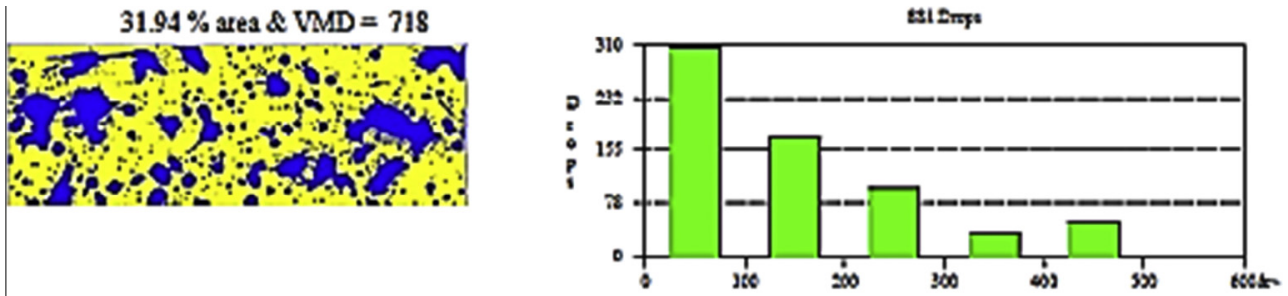

$30.70 \%$ area $\& \mathrm{VMD}=611$
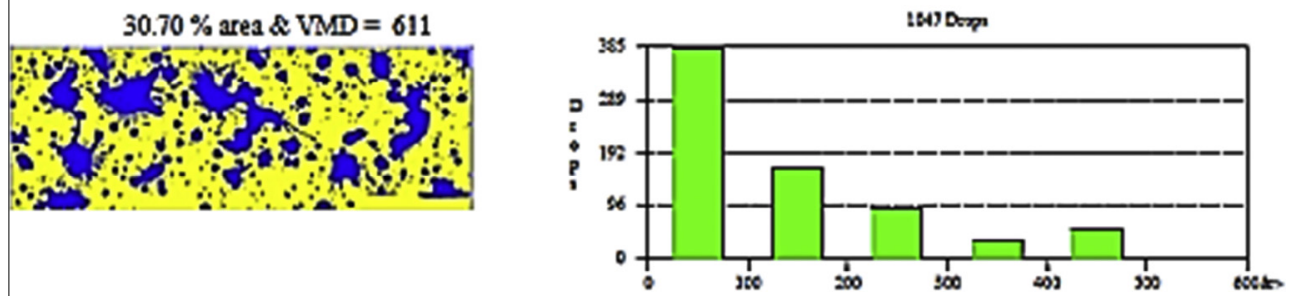

$29.98 \%$ area \& VMD $=619$
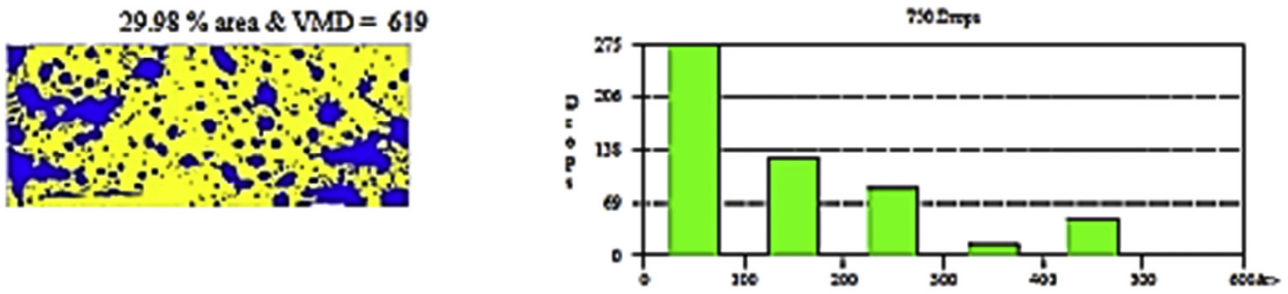

$21.63 \%$ area \& VMD $=617$

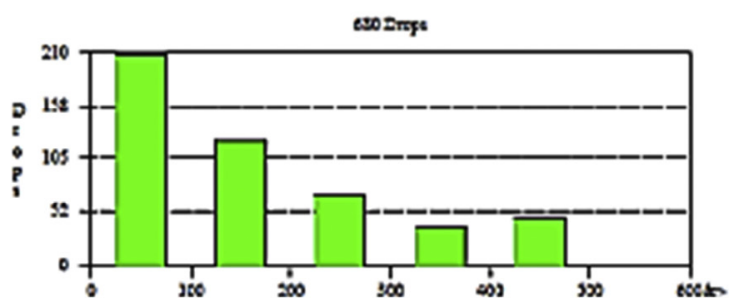

Fig. 2. Droplet Scan ${ }^{\circledR}$ Interface screen grab from cards scanned into the computer. The bar graphs show the percentage of the spray volume across specific droplet sizes in $\mu \mathrm{m}$. This 8008 nozzle coverage on WSP shows a majority of the deposits were between 500 and $600 \mu \mathrm{m}$.

to IJ and SNP which operate on a binary system (e.g. the amount of black area on white area). All of the five systems have been shown to provide acceptable results in previous studies. Rather than just using one system as a baseline, multiple comparison systems were included to create a baseline that covers the potential ranges in data that could be measured with which to compare SnapCard against. This baseline is useful to protect against the error and bias inherent with any one type of system. The trends across imaging systems and SNP were consistent which has been observed in other comparisons of imaging systems for droplet deposition (Hoffmann and Hewitt, 2005; Cunha et al., 2011; Cunha et al., 2013).

\subsection{Kromekote ${ }^{\circledR}$ coverage}

Measured coverage on Kromekote ${ }^{\circledR}$, as with WSP were not similar across software types, but unlike coverage measured on WSP, resulted in lower standard deviations across nozzle type. SNP was not similar to IJ for four of the six nozzle types (11003, 11006,8008 , and 6510) even though it is based on an IJ platform. This suggests that while the application may have been tested with IJ in early development (Nansen et al., 2015) the two systems are in fact not identical. Unlike with WSP, DRP was only able to measure the 11001 , likely due to a higher resolution than the other software used in the study, unlike the other systems due to its resolution.

\subsection{Imaging system features and evaluations}

The imaging systems did not show full agreement within each nozzle type, but for a majority of the results across spray qualities and collector types, results were similar. There are many studies that show the usefulness of SWT and DRP (Hoffmann and Hewitt, 2005; Wolf, 2003; Mierzejewski, 1991) for characterising and calibrating sprayers. SWT, DVA and DRP were developed specifically to measure the evenness of the droplet spectrum across a boom, mainly for aerial application. This feature is useful for that application, but in the case of DRP, prevents it from measuring densely sprayed collectors. Even though DRP was not able to scan each collector, when the collector was not densely covered, DRP provided similar results with the other imaging systems. DRP was the easiest of these systems to use as it had the ability to scan several sprayed collectors at once (Fig. 2). However, the DRP resolution limits its value. DRP features an actual photo on the screen of the scanned collector which allows for the user to easily see what was measured, which could be quickly changed if needed. Both DRP and DVA require a paid license, which also includes support and help if needed.

For pure image analysis, an Image J based system appears to be the way forward, especially given its free cost and ability to measure even the most saturated cards. IJ has wide application across disciplines and can be fine-tuned and designed for any purpose one 
may have for research (Rasband, 2008). DEP was a useful program to provide more than just coverage results and is freely available like IJ. DEP, unlike IJ is able to process cards with much less hassle, and given its greater output of results beyond simply providing coverage results, make it a more appealing system to measure sprayed cards.

\subsection{Assessment of SnapCard}

The choice of the ASABE/ANSI S572.1 reference nozzles was to assess SNP against the other imaging software types across an array of spray qualities. The ASABE/ANSI S572.1 reference nozzles ensure that each spray quality commonly used in agriculture is included to accurately make the assessment of this new novel smartphone App. The overall assessment of SNP is positive because it measures coverage similarly to other imaging systems on the market. Across both artificial collector types, SNP fell within one standard deviation of the means for each nozzle type. This demonstrates the precision of coverage data from the system.

Fig. 1 shows the easy to use format, and the process of scanning in a sprayed card. The portable features of the program make it a useful addition to the growing number of freely available smart phone applications in use for modern day agriculture. Its ability to quickly provide repeatable measurements from sprayed artificial collectors can replace many of the look-up diagrams or manual counting and prediction methods of the past (Syngenta, 2002). The predicted spray coverage function was not evaluated in this study, but is an additional interface available for growers and applicators who install the App to their phones.

\section{Conclusions}

SnapCard is a useful new addition to the growing number of freely available technology solutions at the farm level. It provides coverage results that are reliable and compare with other existing software systems on the market today. Though imaging systems evaluated in this study lacked similarity of measured coverage, the trends observed in this study provide a useful barometer for technology selection. SNP results with identical sprayed collectors was close to results of other imaging software currently used, which makes it a useful addition to any smartphone user's mobile measurement tools.

\section{Acknowledgements}

The authors acknowledge the Grains Research and Development Corporation of Australia (GRDC) for their support of this work through the project titled "Options for improved insecticide and fungicide use and canopy penetration in cereals and canola." The authors also would like to thank John Moore of the Department of Agriculture and Food WA for his support of travel in this study.

\section{References}

Ahlers, K.D., Alexander, D.R., 1985. Microcomputer based digital image processing systems developed to count and size laser-generated small particle images. Optic. Eng. 24, 1060-1065.

ASAE, 2009. Spray Nozzle Classification by Droplet Spectra. Standard 572.1 American Society of Agricultural and Biological Engineers, St. Joseph, MI.
Bouse, L.F., Kirk, I.W., Bode, L.E., 1990. Effect of spray mixture on droplet size. Trans. ASAE 33, 783-788.

Carlton, J.B., 1967. Continuous recording of $\mathrm{H}_{2} \mathrm{O}$ spray spot images across the sprayed swath on 35-mm film. J. Econ. Entomol. 60, 744-748.

Carlton, J.B., Bouse, L.F., 1981. Characterizing spray deposit on film by light transmission. Trans. ASAE 24, 277-280.

Courshee, R.J., 1960. Some aspects of the application of insecticides. Annu. Rev. Entomol. 5, 327-352.

Cunha, J.P.A.R., Farnese, A.C., Olivet, J.J., 2013. Computer programs for analysis of droplets sprayed on water sensitive papers. Planta Daninha 31, 715-720.

Cunha, M., Carvalho, C., Marcal, A.R.S., 2011. Assessing the ability of image processing software to analyse spray quality on water-sensitive papers used as artificial targets. Bios. Eng. 111, 11-23.

Degre, A., Mostade, O., Huyghebaert, B., Tissot, S., Debouche, C., 2001. Comparison by image processing of target supports of spray droplets. Trans. ASAE 44, $217-$ 222.

Ferguson, J.C., O’Donnell, C.C., Chauhan, B.S., Adkins, S.W., Kruger, G.R., Wang, R. Urach Ferreira, P.H., Hewitt, A.J., 2015. Determining the uniformity and consistency of droplet size across spray drift reducing nozzles in a wind tunnel. Crop Prot. 76, 1-6.

Franz, E., 1993. Spray coverage analysis using a hand-held scanner. Trans ASAE 36 $1271-1278$.

Hewitt, A.J., Meganasa, T., 1993. Droplet distribution densities of a pyrethroid insecticide within grass and maize canopies for the control of Spodoptera exempta larvae. Crop Prot. 12, 59-62.

Hewitt, A.J., 2010. Tracer and collector systems for field deposition research. Asp. Appl. Biol. 99, 283-289.

Higgins, A.H., 1967. Spread factors for technical malthion. J. Econ. Entomol. 62, 912 916.

Hill, B.D., Inaba, J., 1989. Use of water-sensitive paper to monitor the deposition of aerially applied insecticides. J. Econ. Entomol. 82, 974-980.

Hoffmann, W.C., Hewitt, A.J., 2005. Comparison of three imaging systems for watersensitive papers. Appl. Eng. Agric. 21, 961-964.

Johnstone, D.R., 1960. Assessment Techniques 2. Photographic Paper. CPRU Porton Report No. 177. Mimeographed, 13pp.

Kenward, M.G., Roger, J.H., 1997. Small sample interference for fixed effects from restricted maximum likelihood. Biometrics 53, 983-997.

Knoche, M., 1994. Effect of droplet size and carrier volume on performance of foliage-applied herbicides. Crop Prot. 13, 163-178.

Leading Edge Associates, 2015. Drop Vision ${ }^{\circledR}-$ AG Available from $<$ http://www leateam.com/pdf/DropVision-AG-Literature.pdf> (Accessed October 20, 2015).

Lee, C.W., Parker, J.D., Baldrey, D.A.T., Molyneux, D.H., 1978. The experimental application of insecticides from a helicopter for the control of riverina populations of Glossina tachinoides in West Africa. II Calibration of Equipment and Insecticide Dispersal. Pestic. Appl. News Sheets 24, 404-422.

Mierzejewski, K., 1991. In: Parker, B.L., Skinner, M., Lewis, T. (Eds.), Aerial Spray Technology: Possibilities and Limitations for Control of Pear Thrips in Towards Understanding Thysanoptera General Technical Report NE-147. USDA Forest Service, New England, USA.

Nansen, C., Ferguson, J.C., Moore, J., Groves, L., Emery, R., Garel, N., Hewitt, A., 2015. Optimizing pesticide spray coverage using a novel web and smartphone tool. SnapCard. Agron. Sust. Dev. 35, 1075-1085.

Osteen, C.D., Fernandez-Cornejo, J., 2013. Economic and policy issues of U.S agricultural pesticide use and trends. Pest Manage. Sci. 69, 1001-1025.

Rasband, W.S., 2008. ImageJ. U.S. National Institutes of Health, Bethesda, Maryland, USA. 1997-2008.

Sidak, Z., 1967. Rectangular confidence regions for the means of multivariate normal distributions. J. Am. Stat. Soc. 62, 626-633.

Syngenta, 2002. Water-Sensitive Paper for Monitoring Spray Distributions. $\mathrm{CH}-$ 4002. Syngenta Crop Protection AG, Basle, Switzerland.

Turner, C.R., Huntington, K.A., 1970. The use of a water sensitive dye for the detection and assessment of small spray droplets. J. Agric. Eng. Res. 15, 385387.

Uk, S., Courshee, R.J., 1982. Distribution and likely effectiveness of spray deposits within a cotton canopy from fine ultralow-volume spray applied by aircraft. Pest. Sci. 13, 529-536.

Wolf, R.E., 2003. Assessing the ability of DropletScan ${ }^{\text {mix }}$ to analyze spray droplets from a ground operated sprayer. Appl. Eng. Agric. 19, 525-530.

Wolf, T.M., Harrison, S.K., Hall, F.R., Cooper, J., 2000. Optimizing postemergence herbicide deposition and efficacy through application variables in no-till systems. Weed Sci. 48, 761-768.

Zhu, H., Salyani, M., Fox, R.D., 2011. A portable scanning system for evaluation of spray deposit distribution. Comp. Elect. Agric. 76, 38-43. 